\title{
PROGRAMA BRASIL SEM MISÉRIA E AS ESTRATÉGIAS DE COMUNICAÇÃO E MOBILIZAÇÃO SOCIAL: UM OLHAR PARA A INCLUSÃO SOCIAL E PRODUTIVA
}

\author{
ÂNGELA PEREIRA \\ Universidade Federal de Santa Maria \\ Santa Maria, Rio Grande do Sul, Brasil \\ E-mail: abpereira@emater.tche.br \\ DAIANE LORETO DE VARGAS \\ Universidade Federal de Santa Maria \\ Santa Maria, Rio Grande do Sul, Brasil \\ E-mail: loretodevargas@gmail.com
}


PROGRAMA BRASIL SEM MISÉRIA E AS ESTRATÉGIAS DE COMUNICAÇÃO E MOBILIZAÇÃO SOCIAL: UM OLHAR PARA A INCLUSÃO SOCIAL E PRODUTIVA

Resumo: O presente trabalho discute, de forma teórica e prática, as estratégias de comunicação, mobilização social e o processo de vinculação que ocorre entre agricultores em situação de extrema pobreza, os extensionistas e as instituições locais que participam da organização do Fomento/ PBSM.

Palavras-chaves: Pobreza Rural, Mobilização Social, Comunicação, Vinculação.

PROGRAMA BRASIL SIN MISERIA Y LAS ESTRATEGIAS DE COMUNICACIÓN Y MOVILIZACIÓN SOCIAL: UNA MIRADA A LA INCLUSIÓN SOCIAL Y PRODUCTIVA

Resumen: En consecuencia, este documento analiza las estrategias de comunicación, teóricas y prácticas, la movilización social y el proceso de unión que se produce entre los agricultores en situación de pobreza extrema, los agentes de extensión y las instituciones locales que participan en la organización de Desarrollo / PBSM .

Palabras clave: pobreza rural, la movilización social, comunicación, vinculación.

BRAZIL WITHOUT POVERTY PROGRAM AND STRATEGIES FOR COMMUNICATION AND SOCIAL MOBILIZATION: A LOOK AT SOCIAL INCLUSION AND PRODUCTIVE

Abstract: Accordingly, this paper discusses theoretical and practical, communication strategies, social mobilization and the bonding process that occurs between farmers in extreme poverty, extension workers and local institutions involved in the organization of Development / PBSM .

Keywords: Rural Poverty, Social Mobilization, Communication, Linking. 


\section{INTRODUÇÃO}

A pobreza extrema é um fenômeno histórico e social, consequência de um processo de desenvolvimento concentrador de renda, com raízes históricas estruturais de exclusão social. Fatores que podem ser considerados como inibidores da cidadania, que resultaram nas desigualdades sociais e no elevado índice de concentração de capital que prevalece em nossa sociedade. Portanto, este fenômeno se configura num problema social, que necessita de estratégias de superação, como uma ação conjunta de várias políticas públicas.

A pobreza configura-se como um fenômeno com características diferenciadas, presente em maior número no meio rural do que no espaço urbano, já que $70 \%$ dos 1,44 milhões de habitantes que vivem em condição de pobreza nos países em desenvolvimento residem em zonas rurais (RELATÓRIO DE POBREZA RURAL, 2011). No meio rural a pobreza está relacionada a diversos fatores, como: a dificuldade de acesso as políticas públicas, distâncias geográficas, baixa escolaridade, falta de emprego e a dificuldade de manter a família com os recursos adquiridos somente do trabalho na propriedade rural.

Nesse sentido, se faz necessário, à participação social dos indivíduos e grupos que vivem este processo de exclusão, tanto nas estratégias como nos programas e nas iniciativas locais. De acordo com Vannuchi et al, (2008), a participação cidadã e a capacidade de auto-organização das comunidades são elementos fundamentais no desenvolvimento, como as dinâmicas culturais e políticas que transformam a vida social. Segundo os autores, os aportes externos são importantes, mas devem existir como complementos a uma dinâmica que pertence à própria comunidade.

A pobreza como uma questão relativa a democracia e a cidadania, desafia a sociedade na busca de estratégias de superação nas desigualdades sociais. Para Maluf e Mattei (2009), as políticas públicas devem descentralizar o poder para os locais onde ocorrem os problemas e a sociedade civil deve ser estimulada a participar das estratégias de superação da pobreza.

Segundo o Instituto Brasileiro de Geografia e Estatística (IBGE), 46,7\% das pessoas em situação de extrema pobreza no Brasil residem em áreas rurais. No Rio Grande do Sul a dimensão da pobreza rural pode ser expressa por três indicadores principais: a) 149.000 famílias rurais estão inscritas no CADÚNICO (MDS, 2012); b) 77.000 famílias rurais recebem Bolsa Família (MDS 2012) e; c) cerca de 30.000 domicílios estão enquadrados como de extrema pobreza (IBGE, 2010). 
PROGRAMA BRASIL SEM MISÉRIA E AS ESTRATÉGIAS DE COMUNICAÇÃO E MOBILIZAÇÃO SOCIAL

A partir de uma analise desse contexto, o Plano Brasil Sem Miséria (PBSM), criado em 2011, tem como principal objetivo superar a pobreza extrema no Brasil. O Plano se organiza em três eixos: garantia de renda, acesso a serviços públicos e inclusão produtiva. Cada um dos eixos possui estratégias diferenciadas de superação da pobreza. No eixo inclusão produtiva, o qual nos interessa para análise e discussão do presente trabalho, destaca-se o programa Fomento.

O Fomento/PBSM propõe duas ações essenciais: a assistência técnica e extensão rural e a transferência de recursos não reembolsáveis diretamente para as famílias beneficiárias. Esses recursos, ao apoiarem o desenvolvimento do projeto produtivo de cada família, permitem ampliar ou diversificar a produção de alimentos, gerando renda e promovendo segurança alimentar e nutricional.

No Rio Grande do Sul, a Secretaria de Desenvolvimento Rural, Pesca e Cooperativismo - SDR, tem a Associação Riograndense de Empreendimentos de Assistência Técnica e Extensão Rural - EMATER/RS como executora do Fomento/PBSM, a partir de projetos de inclusão produtiva e da assistência técnica e social às famílias em situação de extrema pobreza. Esta política pública está sendo operacionalizado em 23 municípios da região de Santa Maria, atendendo 365 famílias rurais em situação de extrema pobreza.

A partir da contextualização das ações práticas deste programa, o presente trabalho tem como objetivo discutir a operacionalização do Fomento/ PBSM, especialmente no que se refere à mobilização social e aos processos comunicativos imbricados na efetivação dessa política pública. Assim como, visa analisar a atuação da assistência técnica e extensão rural como mediadora na execução dos projetos de inclusão social e produtiva.

Os processos comunicativos, emanados no programa Fomento/PBSM, atingem públicos diferenciados, desde extensionistas rurais, gestores locais, organizações municipais e o seu público alvo, que são as pessoas do meio rural que vivem em situação de pobreza extrema. Dessa forma, as estratégias comunicacionais para estes públicos são utilizadas de forma distintas.

O que se percebe, é que em todos os momentos o programa referido visa à mobilização social, através de ações comunicativas que sensibilize tanto gestores, quando os agricultores em vulnerabilidade social para que acessem ao Fomento/ PBSM e consigam, através dos recursos disponibilizados e do serviço de assistência técnica e extensão rural, melhorar a qualidade de vida da família. 
A mobilização social dinamiza e potencializa a participação das organizações sociais, gerando vínculos entre as organizações e seu público, para juntos construírem as mudanças das realidades sociais. Os vínculos geram co-responsabilidades dos atores envolvidos, que entendem a sua participação como essencial para o sucesso do projeto (HENRIQUES, et. al, 2002).

A partir deste contexto, o processo de mobilização social exige uma comunicação dialógica, libertadora e educativa que promova o encontro dos sujeitos interlocutores. Isso "significa dizer que a existência humana é, por si, uma existência dialógica, porque o homem é um ser de relação" (HENRIQUES, et. al, 2002, p, 20).

Nesse sentido, o documento a seguir apresenta no Capítulo I, o Programa Brasil sem Miséria; no Capítulo II, as Ações Midiáticas e Impacto Social do Fomento/ PBSM, dividido em subtemas: Ações para Sensibilizar os extensionistas da Emater e os Gestores Municipais; Ações para Sensibilizar os Agricultores em Situação de Extrema Pobreza; Ações para se Legitimar na Sociedade e ainda as considerações finais.

\section{CARACTERIZAÇÃO DO PROGRAMA BRASIL SEM MISÉRIA}

O Plano Brasil Sem Miséria (PBSM), criado em 2011, tem como principal objetivo superar a pobreza extrema no Brasil. O Plano se organiza em três eixos: garantia de renda, para alívio imediato da situação de extrema pobreza; acesso a serviços públicos, para melhorar as condições de educação, saúde e cidadania das famílias; e um terceiro de inclusão produtiva, para aumentar as capacidades e as oportunidades de trabalho e geração de renda entre as famílias mais pobres.

O Programa Fomento/ PBSM faz parte do eixo de inclusão produtiva rural. A iniciativa, responsabilidade do Ministério do Desenvolvimento Social (MDS) e do Ministério do Desenvolvimento Agrário (MDA), propõe duas ações essenciais: a assistência técnica e extensão rural e a transferência de recursos não reembolsáveis (fundo perdido) diretamente para as famílias beneficiárias. O programa de inclusão produtiva foi criado por meio da Lei 12.512/ 2011 e é regulamentado pelo Decreto 7.644/2011.

Conforme o Boletim Informativo do MDA-MDS (2014), o programa do Fomento/PBSM, foi construído afim de, atender a uma demanda de assistência técnica e extensão rural, a um público que até então não era um pú- 
blico prioritário nas ações de ATER e também não acessava recursos para a produção local de alimentos. Nesse sentido, o programa passa a dar visibilidade e oportuniza o acesso aos diferentes programas sociais.

Tendo como objetivos: o acesso a oportunidades de ocupação às famílias beneficiárias e a promoção de sua segurança alimentar e nutricional, com a ampliação e a diversificação da produção de alimentos e das atividades produtivas geradoras de renda; a incorporação de novos conhecimentos às atividades produtivas que as famílias beneficiárias já desenvolvem ou a estruturação de novas atividades produtivas; e a inserção das famílias beneficiárias em políticas públicas de promoção social.

Essas famílias possuem vulnerabilidades específicas, que fizeram com que não fossem incluídas nas políticas públicas ou tivessem dificuldades para a superação de sua condição de pobreza. O programa Fomento/PBSM é destinado para famílias rurais com renda per capita de até $R \$ 77,00$ (setenta e sete reais), portadoras de Declaração de Aptidão ao PRONAF (DAP) e inscritos no Cadastro Único de Programas Sociais (CADÙNICO).

Ainda vale considerar que, no programa Fomento/PBSM, assim como, no programa Bolsa Família, a mulher é a beneficiária prioritária, pois, ambos os programas visam ao empoderamento da mulher, a partir de projetos de geração de renda e inclusão produtiva.

\section{AÇÕES MIDIÁTICAS E IMPACTO SOCIAL DO FOMENTO/ PBSM}

Existe um Manual Operacional, criado pelo MDA, MDS e EMATER que esclarece como deve ser operacionalizado o programa Fomento/PBSM, clareando as ações propostas, a metodologia a ser utilizada e o público alvo do programa. Nesse sentido, cabe a este espaço compreender os recursos midiáticos utilizados, as formas de ação dos mesmos e o impacto social que o programa tem gerado.

Para isso, analisa-se o programa, seus objetivos, o nível de mobilização que se consegue atingir e como faz isso, os atores envolvidos nesse processo comunicativo, o público que alcança e as metodologias utilizadas para com este público. Estas são algumas questões que se tenta responder, através da análise prática e da reflexão teórica sobe o programa Fomento/PBSM.

Dessa forma, é importante organizar e clarear as ações práticas realizadas pelo referido programa, apresenta-se a seguir o cronograma de ativida- 
de executadas pelos extensionistas rurais, quadro-1. Onde pode se visualizar através das atividades que ocorre uma ampla interação com o público-alvo.

\begin{tabular}{|c|c|}
\hline Atividade 1.0 & Mobilização e Seleção de Famílias \\
\hline Atividade 1.1 & Diagnóstico da Unidade de Produção Familiar \\
\hline Atividade 1.2 & Orientação para acesso as politicas públicas e capacitação continuada \\
\hline Atividade 1.3 & Elaboração do Projeto de Fomento a atividade produtiva familiar \\
\hline Atividade 1.4 & Acompanhamento e Orientação Técnica \\
\hline Atividade 1.5 & Capacitação com foco no projeto da atividade produtiva \\
\hline Atividade 1.6 & Reunião para avaliação das atividades de ATER \\
\hline
\end{tabular}

Quadro- 1: Cronograma de atividades executadas pelo Fomento/PBSM

Fonte: Adaptado do Manual Operativo do Fomento/PBSM

A partir dos passos apresentados no quadro -1 é provável que ocorra, nas estratégias de comunicação, uma vinculação dos atores envolvidos, através de uma dialogicidade e de práticas participativas com os agricultores em situação de extrema pobreza. As estratégias de mobilização quando geram vínculos transcendem as ações pontuais e buscam a coesão e a co-responsabilidade dos atores sociais (HENRIQUES, el. al, 2002).

Já a relação dialógica é destacada por Freire (1983), que propõe uma relação dialética entre as famílias de agricultores e os extensionistas, que propicie uma construção coletiva de conhecimentos conforme a realidade social das comunidades rurais, oportunizando a troca de saberes e a valorização da cultura local.

No entanto, ao analisar todo o processo comunicativo ao longo das ações realizadas desde o lançamento do programa até sua legitimação para com a sociedade, percebe-se a mistura de práticas difusionistas e participativas. As práticas participativas ocorrem entre os extensionistas e os agricultores, no entanto, a difusão percebe-se nas diretrizes operacionais que conduzem o programa e já vêm delineadas.

\section{1 Ações para Sensibilizar os Extensionistas da Emater e os Gestores Municipais}

O Manual Operacional é apresentado aos extensionistas, que por sua vez, sensibilizam os gestores municipais para aderirem ao programa. Por não ser um público privilegiado nas ações de ATER, os extensionistas precisam ser sensibilizados para trabalhar com os agricultores que vivem em 
extrema pobreza. Para isso, o MDA e o MDS capacitaram num primeiro momento os coordenadores da Emater, que posteriormente, seguem articulando as capacitações regionais para os extensionistas municipais que irão operar o programa.

Esse processo apresenta-se através de cursos de formação, da leitura do manual operativo do programa, de folders, de cartilhas e de vídeos de sensibilização. Além disso, a formação prioriza as políticas públicas de inclusão social, como CADÚNICO e programa Bolsa Família, ou seja, os extensionistas passam a conhecer os programas sociais de enfrentamento à pobreza.

A partir do momento em que os extensionistas já estão sensibilizados, os mesmos passam a trabalhar com os gestores municipais. Num primeiro momento, cria-se dentro dos municípios um grupo gestor, para ajudar na operacionalização do programa. A partir disso, os agentes de ATER apresentam o Fomento/PBSM ao grupo gestor, o qual auxilia na seleção das famílias e na divulgação do mesmo. Como pode ser observado na figura -1 .

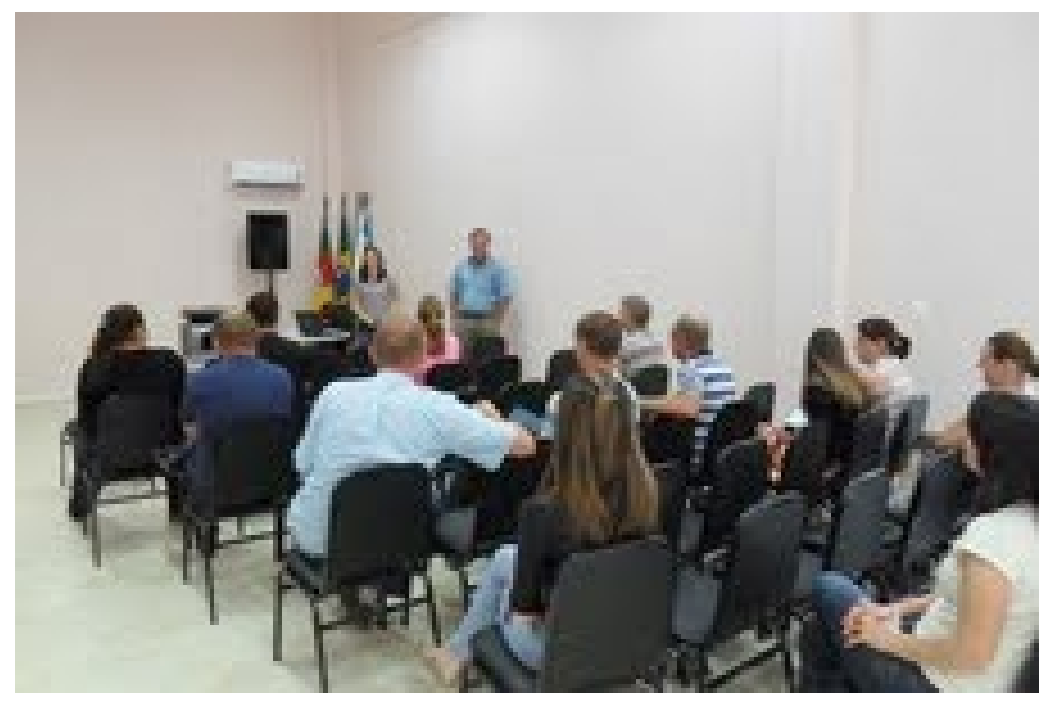

Figura 1: Reunião de externsionistas e lideranças locais

Fonte: Extensionista da Emater, 2014

Para esse trabalho de divulgação, a extensão rural utiliza as estratégias de reunião, com visualização (apresentação de slides) e vídeos de sensibilização. Vale destacar que a construção de um programa de sensibilização visual, amplia a visibilidade do propósito a que pretende atingir, ajudando na criação de laços de identificação dos sujeitos que são mobilizados, no caso, as organizações locais, com o propósito apresentado pela estratégia de comunicação (HENRIQUES et. al., 2002).

Dessa forma, a Emater local realiza uma reunião com as organizações 
municipais, para apresentação e sensibilização dos gestores para adesão ao programa. Essa reunião ocorre entre os extensionistas, prefeito do município, secretaria de assistência social, presidente do sindicato dos trabalhadores rurais, conselheiros municipais da agricultura e da assistência social e outras organizações, lideranças locais.

Nesta reunião é formalizado o grupo gestor local, o qual participa da identificação das comunidades que serão atendidas e seleciona as famílias que serão contempladas pelo programa, respeitando os critérios estabelecidos para a inclusão no programa fomento de enfrentamento a pobreza extrema no meio rural, criadas pelo MDS e MDA.

O próprio Estado pode tomar a inciativa de mobilizar e criar instâncias para oportunizar a participação da sociedade civil nas tomadas de decisões públicas, a partir da criação de conselhos, comitês ou grupos de trabalho. Fato importante para, de alguma maneira, descentralizar o poder na formulação e na implementação de políticas públicas. Esses órgãos sejam de caráter consultivo, deliberativo ou executivo, somente são criados quando a sociedade presencia um regime de democracia (HENRIQUES et. al., 2002).

\subsection{AÇÕES PARA SENSIBILIZAR OS AGRICULTORES EM SITUAÇÃO DE EXTREMA POBREZA}

A execução do Fomento/PBSM ocorre com uma primeira reunião coordenada pelo escritório da Emater local, visando a mobilização e a seleção das famílias, onde se define as famílias que irão participar do programa. A partir disso, se promove o cadastro da DAP e a inclusão no cadastro único para programas sociais.

Depois da adesão ao programa é realizado um diagnóstico, o qual define os projetos produtivos de cada família. Com base no diagnóstico, são decididos os projetos de inclusão produtiva, onde os agricultores participam ativamente na construção das ações a serem realizadas em suas propriedades.

$\mathrm{Na}$ realização do projeto produtivo, os agentes de ATER continuam acompanhando e assessorando as famílias, a partir de reuniões e visitas com foco na atividade produtiva e orientando no acesso as políticas públicas de inclusão social, que oportunizem o empoderamento e a melhoria da qualidade de vida dos beneficiários.

As bases do Manual Operacional apontam para a execução de atividades com uma metodologia participativa e dialógica, que promova a partici- 
pação e valorize as experiências das famílias de agricultores. Nas atividades coletivas, os grupos de agricultores são constituídos com a participação de 10 a 30 participantes, conforme a realidade das comunidades.

Os conteúdos são abordados de acordo com a realidade de cada contexto social e as demandas específicas de cada grupo, valorizando o saber fazer dos atores envolvidos e utilizando as práticas agroecológicas de produção de alimentos, o que caracteriza o programa como participativo, embora venha com um manual estruturado que dá uma orientação em termos gerais sobre a operacionalização do mesmo.

Mesmo que o programa venha, em linhas gerais estruturado, através de um manual de operacionalização, caracterizando-se como difusionista. Ele possibilita a participação dos agricultores na definição dos projetos de inclusão produtiva, assim como, nas temáticas abordadas durante o projeto.

Na mobilização social das famílias em situação de extrema pobreza, os extensionistas priorizam as metodologias dialógicas e participativas, como pode ser visualizado na figura-2, utilizando nas reuniões e oficinas, visualização móvel, slides e vídeos que possibilite a reflexão e promova a participação dos integrantes do projeto Fomento/PBSM nas temáticas de inclusão social e produtiva.

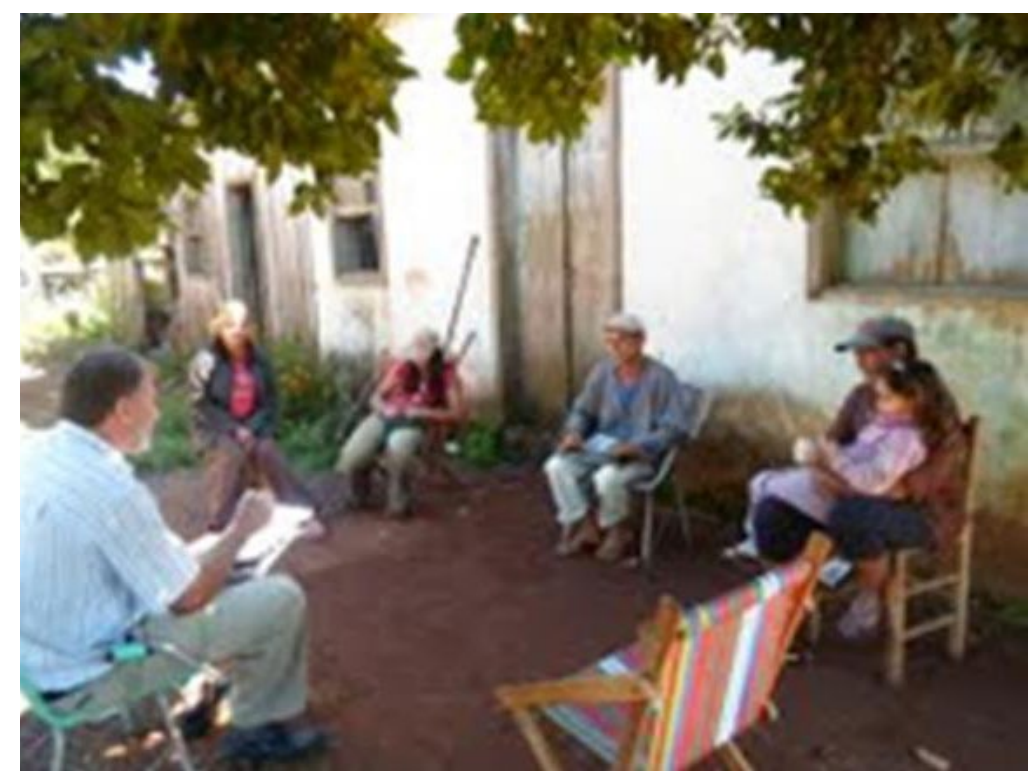

Figura 2: Reunião de extensionistas e agricultores

Fonte: Extensionista da Emater, 2014

Nesse sentido, pode-se observar que a instrumentalização para a comunicação realizada entre extensionistas e o público atendido pelo programa, tem uma construção visual, o que contribui na aproximação e na construção dos laços de confiança e vínculos entre agentes de extensão rural e o os agricultores 
em situação de vulnerabilidade social e produtiva (HENRIQUES et. al., 2002).

Os agentes de ATER criam vínculos com os agricultores, pois, estão em permanente contato com os mesmos, através das visitas e reuniões periódicas, o que possibilita uma comunicação interativa. Essa estratégia é denominada por Henriques et. al., (2002) como comunicação dirigida, onde entra em jogo um importante elemento de ordem comunicativa, a geração de vínculos entre os sujeitos e as causas que estão em jogo.

Estas questões formam elementos que são capazes de manter uma identificação e a defesa de uma determinada causa, podendo inclusive criar um ambiente de cooperação entre os sujeitos que estejam orientados pela mesma causa. Questões que Sodré (2002) denomina de vinculação, pressupondo mais do que um processo interativo, pelo fato de implicar na inserção social do sujeito desde a dimensão imaginária, até a deliberação de seus valores.

Para o autor, as estratégias práticas promovem a construção de vínculos sociais e de uma relação de reciprocidade entre os sujeitos envolvidos em tal processo comunicativo. Onde se torna muito frequente a realização de ações baseadas em uma construção dialógica. Importante e necessária, até mesmo pelo distanciamento que certos povos possuem do aparato moderno de comunicação.

No âmbito dos povos excluídos da conexão com as novas tecnologias e com o mundo globalizado, ainda são as ondas do rádio que possibilitam o meio de comunicação de maior importância. Seja pela carência financeira, tecnológica ou de condições geográficas, como pose ser observado na figura - 3 a condição de extrema pobreza, o fato é que os processos comunicacionais de uma vasta parte da população ainda continuam centrados em formas antigas de espectro midiático (GONÇALVES, 2014).

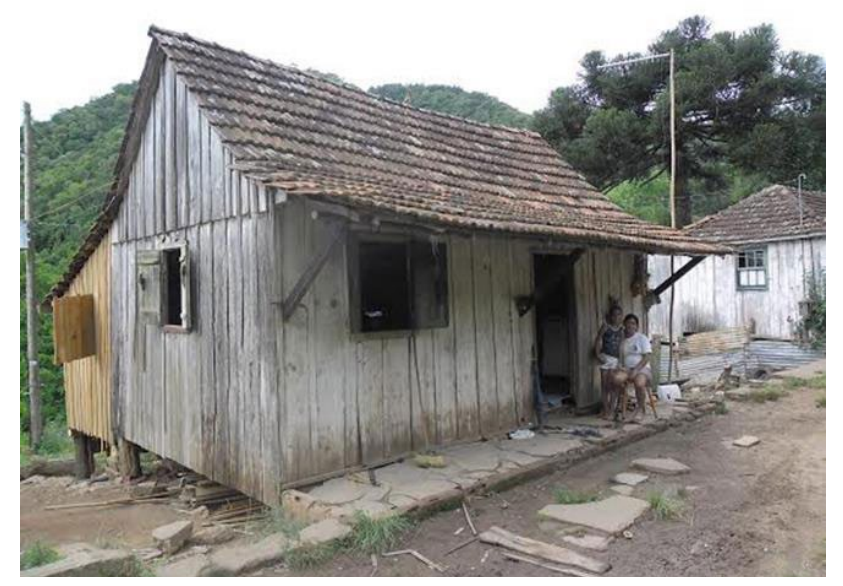

Figura 3: Condição de extrema pobreza dos agricultores

Fonte: Extensionista da Emater, 2014. 
Nesse sentido, conforme diagnóstico realizado com as famílias beneficiárias do programa na região de Santa Maria, sob o aspecto da comunicação, $91,85 \%$ das famílias tem rádio, $89,63 \%$ têm televisão e $84,44 \%$ possuem aparelho celular. O que demonstra a importância do rádio no meio rural, refletindo também na comunicação realizada entre o serviço de extensão rural e a as famílias beneficiárias do Fomento/PBSM, já que os extensionistas utilizam o programa de rádio para agendar reuniões nas comunidades rurais.

\subsection{Ações para se Legitimar na Sociedade}

Durante a execução do programa são gravados vídeos dos projetos nas propriedades das comunidades rurais, destacando a inclusão social e produtiva das famílias participantes do programa. O que possibilita dois ângulos de interpretação, tanto a legitimação de uma política de governo na sociedade, quanto à divulgação de algo que esta dando certo, ao contribuir para o alívio da pobreza no meio rural.

As formas de divulgação do Fomento/PBSM ocorrem através da apresentação nos programas de TV e no site institucional da Emater. O que se configura, nesse caso, por uma sensibilização pela imagem, caracterizada por Sodré (2002) como um processo de veiculação. Tal processo visa à interação entre os sujeitos sociais e as tecnologias da informação, através da imprensa, da televisão e da publicidade, o que se tem chamado de midiatização.

Segundo o autor, o processo de veiculação possibilita que sejam conduzidas as informações entre os sujeitos através do contato com a tecnologia. Para Henriques et. al., (2002), a divulgação pública de um fato, que traga de forma intrínseca estratégias de mobilização social, além de dar visibilidade a tal fato, pode sustentar uma legitimidade frente ao público que assiste.

\section{CONSIDERAÇÕES FINAIS}

Constata-se que a operacionalização do Programa Fomento/PBSM foi favorecida em função da ampla divulgação pelas mídias sociais e pelos meios de comunicação de massa, do Plano Brasil Sem Miséria, por ser um dos eixos prioritários do Governo Federal.

O Fomento/PBSM prevê atividades coletivas que oportunizam a aproximação das famílias em situação de extrema pobreza, fortalecendo os vínculos entre as mesmas e garantindo sua visibilidade por outros órgãos sociais 
do município. Também gera vínculos e co-responsabilidade entre os agentes de ATER e os agricultores.

Percebe-se que a metodologia de sensibilização do programa inicia com bases difusionistas e evolui para uma ação participativa, quando possibilita a interação entre extensionistas e os agricultores, bem como, a construção partilhada nos projetos de inclusão produtiva que serão efetivados na unidade de produção familiar.

A partir da analise desse programa, fica claro que o conhecimento da realidade (pobreza rural) é fundamental para ir além da execução de políticas públicas ou de implantação de projetos que não condizem com o interesse das famílias em situação de pobreza.

É preciso avançar na construção de projetos e planos municipais articulados localmente, com a participação de diferentes segmentos governamentais e da sociedade civil, numa ação integrada e fortalecida de mobilização social que contemple o anseio daqueles que hoje vivem em situação de pobreza ou de extrema pobreza.

\section{REFERÊNCIAS}

BAITELLO JUNIOR, N. O tempo lento e o espaço nulo: mídia primária, secundária e terciária. 2000. Disponível em: http://www.cisc.org.br/portal/index.php/pt/biblioteca/view.download/7-baitello-junior-norval/10-o-tempo-lento-e-o-espaco-nulo-midia-primaria-secundaria-e-terciaria.html. Acesso: 24 de jun. 2014.

FREIRE, P. Extensão ou comunicação? Rio de Janeiro: Paz e Terra, 1983.

GONÇALVES, D. C. Midiatização e contexto rural: análise dos usos e apropriações de dispositivos midiáticos em comunidades da Reserva Extrativista Chico Mendes, Acre. (Dissertação de Mestrado). UNISINOS. Programa de Pós-Graduação em Ciências da Comunicação. São Leopoldo, RS. 2014.

HENRIQUES, M. et. al. Comunicação e estratégias de mobilização social. Gênesis, Belo Horizonte, 2002.

MALUF, R; MATTEI, L. Elementos para construção de uma agenda de políticas públicas para o enfrentamento da pobreza rural. Série Desenvolvimento Rural Sustentável: pobreza rural, concepções, determinantes e proposições para a construção de uma agenda política. 2009.

Manual Operativo. Programa de Fomento à Inclusão Produtiva para Agricultores (as) Familiares e Indígenas em Situação de Extrema Pobreza no RS. Porto Alegre, 2013.

Programa Fomento as Atividades Produtivas. Informativo nº 6, 2014.

Programa Fomento as Atividades Produtivas. Informativo nº 7, 2014.

SODRÉ, M. Antropológica do espelho: uma teoria da comunicação linear e em rede. Edi- 
PROGRAMA BRASIL SEM MISÉRIA E AS ESTRATÉGIAS DE COMUNICAÇÃO E MOBILIZAÇÃO SOCIAL

tora Vozes, Petrópolis, 2002.

VANNUCHI, P; et al, Política nacional de apoio ao desenvolvimento local. São Paulo, outubro de 2008.

\section{Ângela Pereira}

Extensionista da EMATER/RS; Mestranda em Extensão Rural - UFSM; E-mail: abpereira@emater.tche.br

\section{Daiane Loreto de Vargas}

Tecnóloga em Agropecuária - UERGS; Doutoranda em Extensão Rural - UFSM; E-mail: loretodevargas@gmail.com 